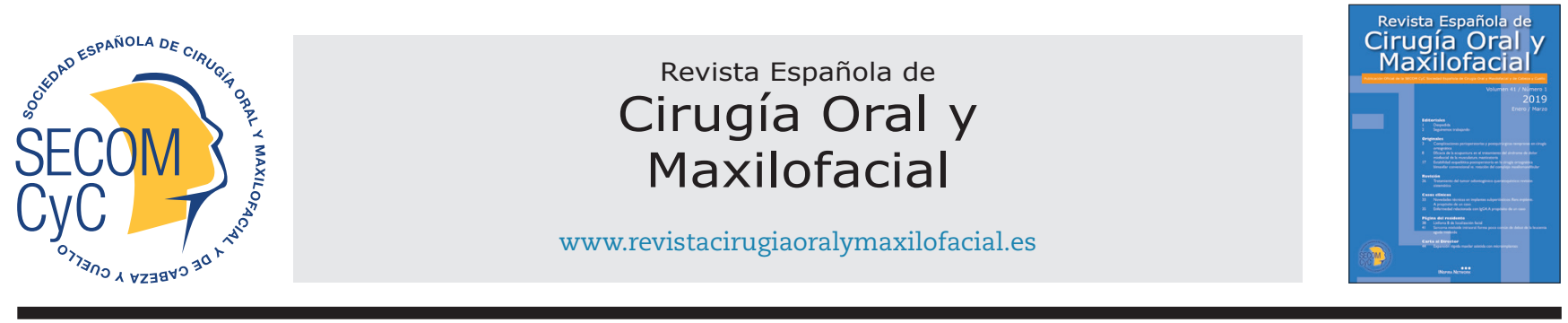

\title{
Editorial
}

\section{Vigésimo Quinto Congreso de la Sociedad Española de Cirugía Oral y Maxilofacial y de Cabeza y Cuello, Sevilla, 13-15 de junio de 2019}

Un año más, el encuentro por antonomasia de los Médicos Especialistas en Cirugía Oral y Maxilofacial españoles, que este año ha tenido lugar en Sevilla durante los días 13 al 15 de junio, ha supuesto un éxito formidable en términos de asistencia y participación de los miembros de la Sociedad Española de Cirugía Oral y Maxilofacial y de Cabeza y Cuello (SECOM CyC) y de otras especialidades afines.

Desde el Comité Editorial de la Revista Española de Cirugía Oral y Maxilofacial (RECOM) queremos felicitar efusivamente al Comité Organizador, presidido por el Dr. José Luis Gutiérrez Pérez, y al Comité Científico, presidido por el Dr. Luis Manuel Junquera Gutiérrez, por la calidad exhibida por los ponentes nacionales e internacionales, que expusieron su experiencia en sobresalientes ponencias distribuidas en áreas temáticas.

Sin menoscabo de todos los congresistas que participaron en forma de comunicaciones orales y pósteres, con y sin defensa, que aportaron frescura e ideas nuevas que contribuirán al desarrollo futuro de nuestra especialidad, queremos destacar la aportación de la experiencia clínica de los ponentes oficiales: Pedro Franco (Dallas, EE. UU.), con respecto a la planificación virtual del recambio protésico de la articulación temporomandibular (ATM); Jean Paul Meningaud (París, Francia), abordando nuevas perspectivas en cirugía glandular parotídea y en rejuvenecimiento facial; Luis Vega (Nashville, EE. UU.), en planificación virtual en cirugía ortognática y controversias de nuestra especialidad; Satyesh Parmar (Birmingham, Reino Unido), introduciendo nuevos aspectos en reconstrucción microquirúrgica y de la laringe; Alicia Dean (Córdoba, España), con respecto a la navegación en el tercio medio facial; Julio Acero (Madrid, España), introduciendo el uso de nueva tecnología en el manejo del tercio medio facial; Stanley Liu (Standford, EE. UU.), abordando la cirugía del sueño; Federico Biglioli (Milán, Italia) y Teresa González (Madrid, España) en el manejo de la parálisis facial; Patrick Tonnard (Gent, Bélgica), en técnicas de rejuvenecimiento facial; Ignacio García (Madrid, España) con respecto al uso de nueva tecnología en cirugía craneofacial; Salvatore Sembronio (Udine, Italia), definiendo el rol que sigue teniendo de la cirugía abierta de la ATM por medio de meniscopexia y meniscectomía, entre la artroscopia de la ATM (Raúl González-García [Badajoz, España]) y el recambio protésico articular [Erik Grandquist (Philadelfia, EE. UU.]); o Mercedes Martín (Madrid, España) y Fernando Molina (Méjico), mostrando su experiencia en cirugía primaria del labio y la nariz en los pacientes fisurados, entre otros varios magníficos ponentes.

No podemos obviar el abordaje de la perspectiva de futuro de nuestra especialidad, que expuso el Presidente saliente de la SECOM CyC, el Dr. José Luis López-Cedrún (La Coruña, España), y el viaje antropológico a través de las caras de nuestros antepasados, que nos planteó el Dr. Florencio Monje (Badajoz, España), a la sazón nuevo Presidente de la SECOM CyC a partir de este congreso nacional. Al primero le damos las gracias por el trabajo desarrollado, y al segundo le deseamos toda la suerte para la consecución de los objetivos marcados por la actual Junta en los próximos dos años.

Sevilla, ciudad luminosa, siempre amable y acogedora, ha sido una sede magnífica para la organización de este encuentro entre profesionales y amigos, que han podido disfrutar del saludable equilibrio entre ciencia y ocio. Queremos felicitar al Servicio de Cirugía Oral y Maxilofacial del Hospital Virgen del Rocío por la organización de tal evento, así como a la pasada Junta de la SECOM CyC, a su presidente José Luis López-Cedrún, y a su gerente Eva Caballero, que han trabajado con ahínco en el mismo. El listón está muy alto, pero Cartagena, sede del próximo $26 .^{\circ}$ Congreso Nacional de la SECOM CyC, dispone de todo lo necesario para no quedarse a la zaga: ánimo y suerte también para sus organizadores. 
No queremos dejar pasar la oportunidad de animar a todos los lectores y miembros de la SECOM CyC para que envíen sus mejores trabajos para su publicación en nuestra querida revista. Nos esperan unos años muy interesantes en la consecución de objetivos para RECOM, de la mano de nuestra nueva compañera de viaje, la editorial Inspira Network, y del trabajo desinteresado de un Comité Editorial formado por todos los revisores que aportan su tiempo y esfuerzo en mejorar los manuscritos recibidos. Sin duda, la incorporación del Dr. Pedro Infante Cossío como nuevo Director Adjunto de la RECOM es un activo de primera línea para llevar nuestra revista a cotas superiores.

No podemos olvidar que los ladrillos que configuran la base fundamental de toda revista de prestigio son los trabajos originales de calidad que puedan ser referentes en las diferentes áreas temáticas. Tenemos la mejor de las Especialidades, y España es un referente mundial en Cirugía Maxilofacial y de Cabeza y Cuello. Hagamos, con la impresionante experiencia acumulada de todos los Servicios de nuestro gran país, que nuestra revista sea también un referente de la especialidad a nivel mundial.

Gracias a todos por ese esfuerzo y felicidades por ese sentimiento de pertenencia a un gran colectivo.

Raúl González-García ${ }^{1,2}$

${ }^{1}$ Director de Revista Española de Cirugía Oral y Maxilofacial. ${ }^{2}$ Facultativo Especialista de Área, Servicio de Cirugía Oral y Maxilofacial, Complejo Hospitalario Universitario de Badajoz, Badajoz, España 